\title{
Improvement of the stability of basic mixed oxides used as catalysts for aldol condensation of bio-derived compounds by palladium addition
}

\author{
Laura Faba, Eva Díaz, Salvador Ordóñez* \\ Department of Chemical Engineering and Environmental Technology, University of Oviedo, (Faculty of Chemistry), \\ Julián Clavería s/n, 33006 Oviedo, Spain
}

\section{A R T I C L E I N F O}

Article history:

Received 26 February 2013

Received in revised form

15 June 2013

Accepted 18 June 2013

Available online 4 July 2013

Keywords:

Base-metal bifunctional catalysts

Biomass upgrading

2nd Generation biofuels

Deactivation in aldol condensation reactions

Furfural

Hydrogen-promoted

aldol condensation

\begin{abstract}
A B S T R A C T
Aqueous-phase aldol condensation of biomass-derived ketones and aldehydes is a key step in the preparation of fuels and chemicals from renewable resources. Furfural-acetone aldol condensation yielding $\mathrm{C}_{8}$ and $\mathrm{C}_{13}$ adducts was studied at $323 \mathrm{~K}$ and $1 \mathrm{MPa}$ in a stirred batch reactor. We propose a new strategy for minimizing catalytic deactivation, consisting of modifying catalysts $\left(\mathrm{MgO}-\mathrm{ZrO}_{2}\right.$ and $\left.\mathrm{MgO}-\mathrm{Al}_{2} \mathrm{O}_{3}\right)$ by Pd addition (2\%). This modification slightly changes the morphology and surface chemistry of the supports, leading to changes on the catalysts performance but not reaction mechanism modifications. If condensation is performed in hydrogen atmosphere, the partial hydrogenation of the condensation adducts increases its water solubility, minimizing catalyst deactivation. In that way, the selectivity for $\mathrm{C} 13$ adduct decreases only $25 \%$ between two successive reaction cycles using $\mathrm{Pd} / \mathrm{MgO}-\mathrm{ZrO}_{2}$ catalyst, whereas this decrease is of $90 \%$ for the un-doped mixed oxides. These effects are less marked for the $\mathrm{MgO}-\mathrm{Al}_{2} \mathrm{O}_{3}$ catalyst.
\end{abstract}

(c) 2013 Elsevier Ltd. All rights reserved.

\section{Introduction}

The depletion of fossil fuels reserves and the increasing environmental concerns about green house gases emissions have increased the development of the renewable energies. Among the different alternative sources, biomass is an excellent candidate to produce organic fuels at relevant amounts [1]. The production of 1st-generation liquid biofuels (obtained mainly from food crops such as sugar, oil and cereals) is already a mature technology. However, several drawbacks hinder its industrial development, such as the competition for land and water used for food, the high production and processing costs, and the low efficiency in terms of fraction of biomass carbon atoms transformed into fuels [2]. These disadvantages have stimulated the development of 2nd-generation liquid biofuels. In this way, lignocellulosic feedstock raw materials include by-products (cereal straw, forestry wastes), residues (organic components of municipal solid wastes), and dedicated feedstocks (purpose-grown vegetables).

Huber et al. [3] proposed a process which transforms the carbohydrates into C8-C13 alkanes. Cellulosic materials are

\footnotetext{
* Corresponding author. Tel.: +34 985103 437; fax: +34 985103434.

E-mail address: sordonez@uniovi.es (S. Ordóñez). 
transformed by hydrolysis into sugars (C5-C6) and oxidized/dehydrated derivatives of these sugars (furfural, hydroximethylfurfural, etc.). Main chemical routes for the upgrading of these materials involve a first step of o-glycosidic bond hydrolysis, in order to obtain single sugars and functional intermediates of the furfural family [4-6]. These reactions can be performed by acid hydrolysis [7] or by catalytic alternatives, such as hydrolytic hydrogenation [4]. Further aldol condensation of these molecules with acetone and deep hydrogenation lead to C8-C13 n-alkanes, valuable as diesel-quality fuel [8]. During this hydrogenation, carbonyl functional groups are transformed firstly into hydroxyl groups, and secondly into linear alkanes by a desoxygenation.

The reaction between furfural and acetone yielding $C_{8}$, which subsequently reacts with another furfural molecule yielding the $\mathrm{C}_{13}$ adduct, is widely selected as a model aldol condensation reaction [3,9]. This reaction was firstly carried out using homogeneous catalysts, $\mathrm{NaOH}$ or $\mathrm{Ca}(\mathrm{OH})_{2}$. However, the application of the Green Chemistry principles has encouraged the use of heterogeneous catalysts, such as nanosized $\mathrm{Co}-\mathrm{Al}$ spinels or nitrogen-substituted zeolites [10], $\mathrm{Mg}-\mathrm{Zr}$ mixed oxides [11], $\mathrm{WO}_{3}-\mathrm{ZrO}_{2}$ [12] or $\mathrm{Mg}-\mathrm{Al}$ and $\mathrm{Ca}-\mathrm{Zr}$ mixed oxides [13]. However, the challenge is still to find selective and stable catalysts, since significant deactivation by the strong adsorption of the reaction products on the catalyst surface of $\mathrm{Mg}-\mathrm{Zr}$ and $\mathrm{Mg}-\mathrm{Al}$ mixed oxides was observed [13]. Since the final step of the process consists of deep hydrogenation of $\mathrm{C} 8$ and $\mathrm{C} 13$ adducts using an active phase, such as Pd or Pt, integration of both processes is also very attractive. The combination of both reactions consecutively was already studied $[8,12,14]$, but no data on conversions and selectivities were obtained after aldolization reaction. Furthermore, there are discrepancies about the influence of the incorporation of Pd on the surface properties of the basic catalysts, being some authors that observe a decrease in the surface are caused by a partial blockage of some pores [12] whereas other researches indicate that the metal can cause a swelling in the original structure $[15,16]$.

The scope of the present work is to analyze the behavior of different bi-functional catalysts, $\mathrm{Pd} / \mathrm{MgO}-\mathrm{ZrO}_{2}$ and $\mathrm{Pd} / \mathrm{MgO}$ $-\mathrm{Al}_{2} \mathrm{O}_{3}$, containing palladium and basic sites, in the aldol condensation of furfural and acetone. The effect of palladium addition on the catalysts deactivation has been also studied. For this purpose, two situations were considered: performing the reaction at the same operation conditions used for unpromoted catalysts, and using a hydrogen atmosphere for promoting partial hydrogenation of the reaction intermediates.

\section{Methods}

\subsection{Materials and chemicals}

The $\mathrm{MgO}-\mathrm{Al}_{2} \mathrm{O}_{3}$ mixed oxide was prepared using $\mathrm{Mg}\left(\mathrm{NO}_{3}\right)_{2} \cdot 6 \mathrm{H}_{2} \mathrm{O}$ (Fluka, $>99 \%$ ) and $\mathrm{Al}\left(\mathrm{NO}_{3}\right)_{3} \cdot 9 \mathrm{H}_{2} \mathrm{O}$ (Panreac, 98\%), $\mathrm{K}_{2} \mathrm{CO}_{3}$ (Panreac, 99\%) and a $\mathrm{NaOH}$ (Prolabo, 98\%) solution. Magnesia-zirconia $\left(\mathrm{MgO}-\mathrm{ZrO}_{2}\right)$ catalyst was synthesized using magnesium nitrate hexahydrate (Fluka, $>99.0 \%$ ), ziconyl nitrate (Aldrich, hydrated) and the $\mathrm{NaOH}$ (Prolabo, 98\%) solution. The impregnation of Pd was done using a tetraaminopalladium (II) nitrate solution from Aldrich with a metal loading of $10 \%$ by weight.

Concerning to the reactants, furfural and acetone were supplied by Panreac (purity: 98 and 99.5\%, respectively). For calibration, standards of the main products were used: furfurildeneacetone C8 (Alfa Aesar, 98\%) and the dimer 1,5-bis(2furanyl)-1,4-pentadien-3-one, C13 (Acros, 98\%).

\subsection{Catalyst preparation and characterization}

The mixed oxides used as supports for bifunctional catalysts, $\mathrm{MgO}-\mathrm{ZrO}_{2}$ and $\mathrm{MgO}-\mathrm{Al}_{2} \mathrm{O}_{3}$, were synthesized using the techniques described in our previous works [13,14]: $\mathrm{Mg}-\mathrm{Al}$ mixed oxide by co-precipitation at low super-saturation method ( $\mathrm{Mg} / \mathrm{Al}$ atom ratio of 3$)$, whereas the sol-gel technique was chosen to the $\mathrm{Mg}-\mathrm{Zr}$ synthesis $(\mathrm{Mg} / \mathrm{Zr}$ atom ratio of 4$)$.

Bifunctional catalysts (Pd/Mg- $\mathrm{Zr}$ and $\mathrm{Pd} / \mathrm{Mg}-\mathrm{Al}, 2 \%$ mass fraction of $\mathrm{Pd}$ in both cases) were prepared by incipient wetness impregnation of the metal solution onto the supports. Resulting materials were treated in flowing $\mathrm{He}$ $\left(100 \mathrm{~cm}^{3} \mathrm{~min}^{-1}\right)$ with a $2 \mathrm{~h}$ ramp and held for $2 \mathrm{~h}$ at $723 \mathrm{~K}$. Further reduction was carried out in flowing $\mathrm{H}_{2}\left(50 \mathrm{~cm}^{3} \mathrm{~min}^{-1}\right)$ with a heating rate of $5 \mathrm{~K} \mathrm{~min}^{-1}$ from $293 \mathrm{~K}$ to $473 \mathrm{~K}$, holding this temperature during $2 \mathrm{~h}$.

Surface area and pore volume were measured by nitrogen adsorption at $77 \mathrm{~K}$ in a Micromeritics ASAP 2020 surface area and porosity analyzer. The crystallographic structures of the bifunctional catalysts were determined by XRD using a Philips PW 1710 diffractometer, working with the $\mathrm{Cu}-\mathrm{K} \alpha$ line $(\lambda=0.154 \mathrm{~nm})$ in the $2 \theta$ range of $5-85^{\circ}$ at a scanning rate of $2^{\circ} \min ^{-1}$. Likewise, the Pd particle morphology and size distributions were determined by transmission electron microscopy (TEM) in a MET JEOL-2000 EX-II microscope and by $\mathrm{H}_{2}$ chemisorption at $373 \mathrm{~K}$ in the Micromeritics ASAP 2020 apparatus.

The strength and distribution of the basic/acid sites were determined by temperature programmed desorption of preadsorbed $\mathrm{CO}_{2} / \mathrm{NH}_{3}$ in a Micromeritics TPD/TPR 2900. Samples (10 mg) were pretreated in He at $723 \mathrm{~K}$ for $2.5 \mathrm{~h}$ and exposed to a $\mathrm{CO}_{2}$ or $\mathrm{NH}_{3}\left(2.5 \% \mathrm{NH}_{3}\right.$ by volume in $\left.\mathrm{He}\right)$ stream at $323 \mathrm{~K}$ until saturation coverage were reached. Weakly adsorbed $\mathrm{CO}_{2}$ or $\mathrm{NH}_{3}$ was removed by flushing with $\mathrm{He}$ at the same temperature for about $1.30 \mathrm{~h}$. The temperature was then increased at a linear rate of $5 \mathrm{~K} \mathrm{~min}^{-1}$ from $293 \mathrm{~K}$ to $723 \mathrm{~K}$ and the signal of $\mathrm{CO}_{2}$ or $\mathrm{NH}_{3}$ desorbed was monitored by mass spectrometry. The nature of basic sites was corroborated by $\mathrm{CO}_{2}$ chemisorption analyzed by Fourier transform infrared (FTIR) spectroscopy, using a Bruker Vector 22 FTIR spectrophotometer (deuterated triglycine sulfate detector) in the $4000-400 \mathrm{~cm}^{-1}$ range, with a resolution of $2 \mathrm{~cm}^{-1}$ and using 100 scans.

The surface composition of the mixed oxides was measured by X-ray Photoelectron Spectroscopy (XPS), using an SPECS system equipped with a Hemispherical Phoibos detector operating in a constant pass energy, using $\mathrm{Mg}-\mathrm{K} \alpha$ radiation $(h \cdot v=1253.6 \mathrm{eV})$. 
After reaction, catalysts were analyzed by temperatureprogrammed-oxidation (TPO) in order to determine the deposition of heavy compounds on the catalytic surface using the Micromeritics TPD/TPR 2900 device. Samples $(10 \mathrm{mg})$ were pretreated in $\mathrm{He}$ at $673 \mathrm{~K}$ for $1 \mathrm{~h}$. The temperature was then increased at a heating rate of $5 \mathrm{~K} \mathrm{~min}^{-1}$ in an $\mathrm{O}_{2}$ flow $\left(2 \% \mathrm{O}_{2}\right.$ by volume in $\mathrm{Ar}$ ) from $293 \mathrm{~K}$ to $873 \mathrm{~K}$, and the $\mathrm{CO}_{2}$ signal was monitored by mass spectrometry.

\subsection{Reaction studies}

Catalytic activity was studied in a $500 \mathrm{~cm}^{3}$ stirred batch autoclave reactor (Autoclave engineers EZE Seal) equipped with a PID temperature controller and a back pressure regulator. The reactor was loaded with $250 \mathrm{~cm}^{3}$ of an aqueous solution of furfural and acetone (different molar ratios were tested). $500 \mathrm{mg}$ of the catalyst was added (with an average particle diameter of $50-80 \mu \mathrm{m}$ ) and the air was purged out by adding nitrogen up to $5573 \mathrm{kPa}$ for three times before starting the condensation reaction. The reactor was then pressurized to $1013 \mathrm{kPa}$ with $\mathrm{N}_{2}$, heated to reaction temperature and stirred at $105 \mathrm{~s}^{-1}$ for $24 \mathrm{~h}$. In order to check the influence of a reducing atmosphere on catalyst performance, experiments were repeated using $1013 \mathrm{kPa}$ of hydrogen instead of nitrogen.

Samples were taken from the sampling port during the condensation reaction, filtered, extracted in ethyl acetate (volume relation 1:1) and analyzed by FID-GC in a Shimadzu GC-2010, using a CP-Sil 5 CB capillary column as stationary phase. The identification was carried out by ${ }^{1} \mathrm{H}$ NMR as it was detailed in the previous work [13]. The calibration of the GCFID was carried out using standards of the reactants and condensation adducts (when commercially available) or using a numerical approach based on the effective carbon number to determine the effect of partial hydrogenation on the original calibration to apply it for the new component [17]. All the calibrations were based on aqueous solutions, repeating the extraction steps using the procedure explained for reactor samples.

The initial concentration of reactants ( $5 \%$ mass fraction of organic compounds) was chosen in order to avoid the formation of separate organic phases during the experiments, since water solubility of condensation adducts is lower than the corresponding to the reactants. In preliminary experiments, it was observed that higher initial concentrations lead to the formation of independent organic phase (milky aspect of the liquid, formation of large granules of organic phase-catalyst aggregates), whereas these effects were not observed at lower concentrations, even at total reactant conversions.

Catalyst performances were compared both in terms of reactant conversions, as well as and C6 (acetone-acetone), C8 (acetone-furfural) and C13 (furfural-acetone-furfural) adducts selectivities $(\Psi)$, and the results were analyzed using the following expressions,

$\psi_{\mathrm{C} 6} \%=\frac{6 \mathrm{~mol} \mathrm{C} 6}{3 \mathrm{~mol} \mathrm{C} 3_{\mathrm{t}=0}} \cdot 100$

$\psi_{\mathrm{C} 8} \%=\frac{8 \mathrm{~mol} \mathrm{C} 8}{5 \mathrm{~mol} \mathrm{C5} 5_{\mathrm{t}=0}+3 \mathrm{~mol} \mathrm{C} 3_{\mathrm{t}=0}} \cdot 100$
$\psi_{\mathrm{C} 13} \%=\frac{13 \mathrm{~mol} \mathrm{C} 13}{5 \mathrm{~mol} \mathrm{C}_{\mathrm{t}=0}+3 \mathrm{~mol} \mathrm{C} 3_{\mathrm{t}=0}} \cdot 100$

Considering that there are not solubility problems when using ethyl acetate as an extraction solvent, the presence of undesired side reactions, leading to solid deposits on catalyst surface, was checked by the carbon balance, defined as:

$$
\begin{aligned}
& \text { C balance } \% \\
& =\frac{3 \mathrm{~mol} \mathrm{C} 3+5 \mathrm{~mol} \mathrm{C} 5+8 \mathrm{~mol} \mathrm{C} 8+13 \mathrm{~mol} \mathrm{C} 13+6 \mathrm{~mol} \mathrm{C} 6}{3 \mathrm{~mol} \mathrm{C} 3_{\mathrm{t}=0}+5 \mathrm{~mol} \mathrm{C} 5_{\mathrm{t}=0}} \\
& \quad \times 100
\end{aligned}
$$

\section{Results and discussion}

\subsection{Catalyst characterization}

The main morphological parameters of Pd catalysts (obtained by nitrogen physisorption) are summarized in Table 1; for comparison, the textural properties of bulk oxides are detailed in a previous work [13].

XRD diffraction patterns of the catalysts (not shown) used in this work reveal similar trends to those reported for the parent mixed oxides. Concerning to the $\mathrm{Pd} / \mathrm{Mg}-\mathrm{Zr}$, mainly periclase $(\mathrm{MgO})\left(2 \theta=37^{\circ}, 43^{\circ}, 62^{\circ}, 78^{\circ}\right)$ and zirconia phases were detected $\left(2 \theta=30^{\circ}, 49^{\circ}, 50^{\circ}, 58^{\circ}\right)$. In the $\mathrm{Pd} / \mathrm{Mg}-\mathrm{Al}$ sample, periclase and $\alpha-\mathrm{Al}_{2} \mathrm{O}_{3}\left(2 \theta=35^{\circ}, 44^{\circ}, 58^{\circ}\right)$ were detected.

Palladium dispersion was evaluated by three techniques: $\mathrm{XRD}, \mathrm{H}_{2}$ chemisorption and TEM analysis. Results are also summarized in Table 1. Palladium dispersion was determined by the Scherrer equation to the (111) crystallographic plane of $\mathrm{Pd}\left(2 \theta=40.1^{\circ}\right)$, at a scanning rate of $0.002^{\circ} \mathrm{min}^{-1}$ in the range $2 \theta=35-45^{\circ}$. Concerning the hydrogen chemisorptions, a Pd:H stoichiometry of 1:1 was assumed [18]. More than 100 palladium nanoparticles from several TEM images were used for estimating metal dispersion by this technique. TEM analysis revealed the presence of small hemispheric Pd crystallites on the surface of the mixed oxides, as it is shown in Supplementary information (Fig. S1). A good agreement among the three techniques was observed for metal dispersion quantification.

The surface concentration of basic sites, as well as their strength distribution, has been determined by $\mathrm{CO}_{2}$-TPD. Results obtained, in terms of density ( $\mu \mathrm{mol}$ of $\mathrm{CO}_{2} \mathrm{~m}^{-2}$ ), are shown in Fig. 1(a), considering the different types of sites as a function of their desorption temperatures [19]. For comparison purposes, desorption profiles for the parent mixed oxides are also shown. Similar strength distribution was observed, with the highest fraction of them within the temperature range of bidentate carbonates (chelating and bridge types). The presence of palladium leads to a decrease of the surface concentration of basic centers, specifically a $40 \%$ in the $\mathrm{Pd} /$ $\mathrm{Mg}-\mathrm{Zr}$ and more than $60 \%$ in the $\mathrm{Pd} / \mathrm{Mg}-\mathrm{Al}$. These results suggest that these materials keep the capacity of catalyze this condensation (same type of centers) but with lower reaction rates (lower concentration of these sites).

The surface composition and chemical environment of the reticular oxygen atoms were analyzed by XPS (Table 1), being 


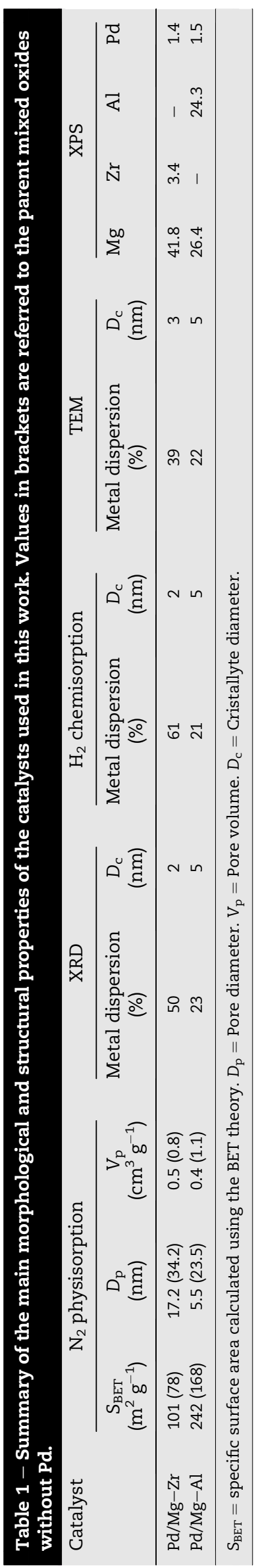

the Pd composition of the materials in a good agreement with the nominal value $(2 \%)$. Concerning to the chemical composition, there is a segregation effect comparing to the mixed oxides that can be caused by a local solubility of metal hydroxides during the impregnation process and the subsequent surface reconstruction. This effect also modifies the specific surface area of the bifunctional catalysts.

Acid properties were analyzed by $\mathrm{NH}_{3}$-TPD. The distribution of these sites and the results are compared with those obtained without palladium in Fig. 1(b) in terms of density of active sites. Acid sites distribution has been estimated according to the criterion of Arena et al. [20]. Pd/Mg-Al catalyst presents higher concentration of acid sites than $\mathrm{Pd} / \mathrm{Mg}-\mathrm{Zr}$, although the strength of these acid sites is lower than the $\mathrm{Mg}-\mathrm{Al}$ support. Medium strength acidity is observed in both catalysts: associated with the presence of acid-basic pairs on the catalyst surface.

\subsection{Catalytic activity under inert and reduction atmosphere}

In order to analyze the effect of the Pd addition on catalyst performance, typical aldol condensation experiment was carried out at 1:1 furfural:acetone ratio (acetone excess for C13 formation). Fig. 2 shows the profiles obtained with $\mathrm{Pd} / \mathrm{Mg}-\mathrm{Zr}$ in terms of C3, C5, C8 and C13 concentrations. The good correspondence between these data and the previous results obtained with the parent mixed oxides [13] leads to guess that the presence of palladium does not modify the general mechanism of the aldol condensation. Final results obtained after $24 \mathrm{~h}$ of furfural-acetone aldol condensation (conversions, selectivities and carbon balances) are summarized in Table 2. Conversion after $24 \mathrm{~h}$ decreases for C5 whereas C3 conversion remains almost stable (even with slight increments in the case of $\mathrm{Pd} / \mathrm{Mg}-\mathrm{Al}$ ) when $\mathrm{Pd}$ impregnated catalysts are compared to mixed oxides. However, differences in product selectivities were more significant. For $\mathrm{Pd} / \mathrm{Mg}-\mathrm{Zr}$, after $24 \mathrm{~h}$ reaction time, the C13 selectivity was about the $50 \%$ of that achieved without metal, whereas an increase of $50 \%$ was observed in the case of the monomer (C8). For the reaction catalyzed by $\mathrm{Pd} / \mathrm{Mg}-\mathrm{Al}$, decreases of $62 \%$ in the final $\mathrm{C} 8$ concentration and almost $95 \%$ in the $\mathrm{C} 13$ were observed when the bifunctional catalyst is compared with the mixed oxide. Thus, the second aldol condensation between $\mathrm{C} 8$ adduct and acetone is almost hindered. However, the acetone selfcondensation yielding mesityl oxide is more notorious, justifying the C3 conversion values. This increase can be justified attending to the decrease of pore diameter after impregnation (Table 1); diacetone alcohol formation is less prone to be limited by pore size than the formation of C8 and C13 adducts. In fact, this is an unusual behavior (usually $\mathrm{S}_{\mathrm{BET}}$ decreases after impregnation), and can be attributed to modifications in the catalytic surface during the impregnation process. This effect also modifies the $\mathrm{Mg} / \mathrm{Zr}$ and $\mathrm{Mg} / \mathrm{Al}$ ratios (decreases of about $60 \%$ after impregnation process): from 117 to 73 for $\mathrm{Pd} /$ $\mathrm{Mg}-\mathrm{Zr}$; and from 1.6 to 1.09 for $\mathrm{Pd} / \mathrm{Mg}-\mathrm{Al}$ (Table 1).

The low C13/C8 ratio (from 3.9 to 1.7 for the $\mathrm{Mg}-\mathrm{Zr}$ and $\mathrm{Mg}-\mathrm{Al}$ mixed oxides, respectively, to 1 and 0.25 for $\mathrm{Pd} / \mathrm{Mg}-\mathrm{Zr}$ and $\mathrm{Pd} / \mathrm{Mg}-\mathrm{Al}$, respectively) is explained considering the highest extent of the retroaldolization reaction. The retro- 

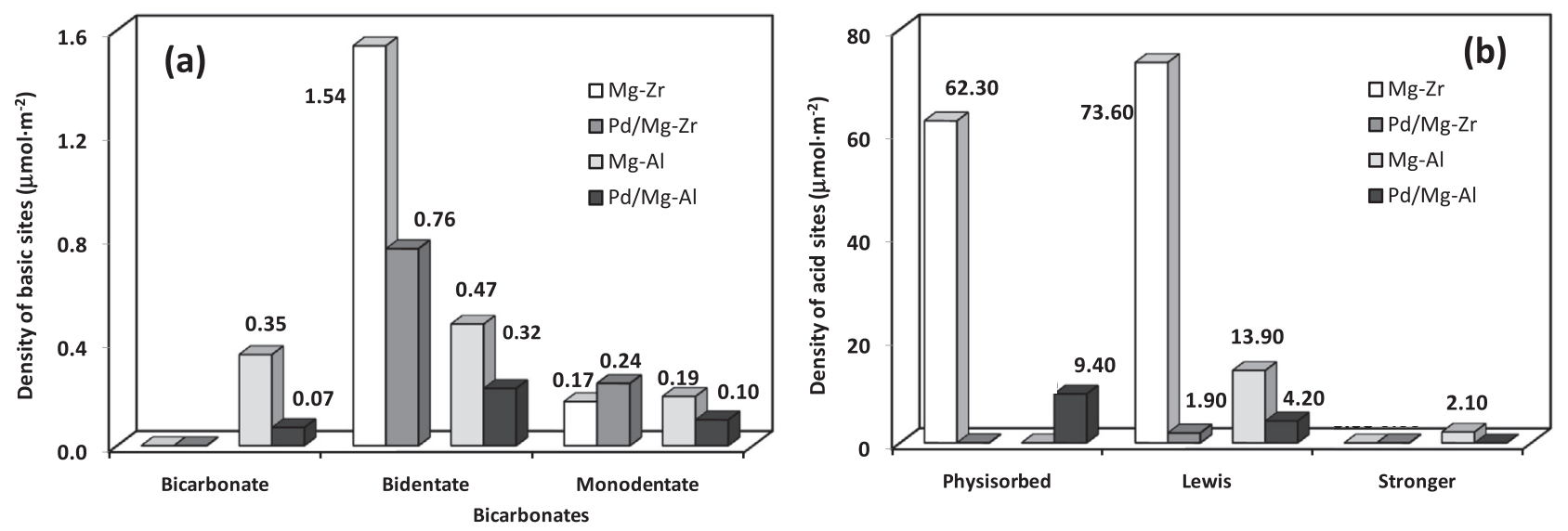

Fig. 1 - Comparison of the density distribution of different active centers between bifunctional catalysts and mixed oxides: basic sites (a) and acid sites (b). (Results related to bulk materials are summarized from Ref. [13]).

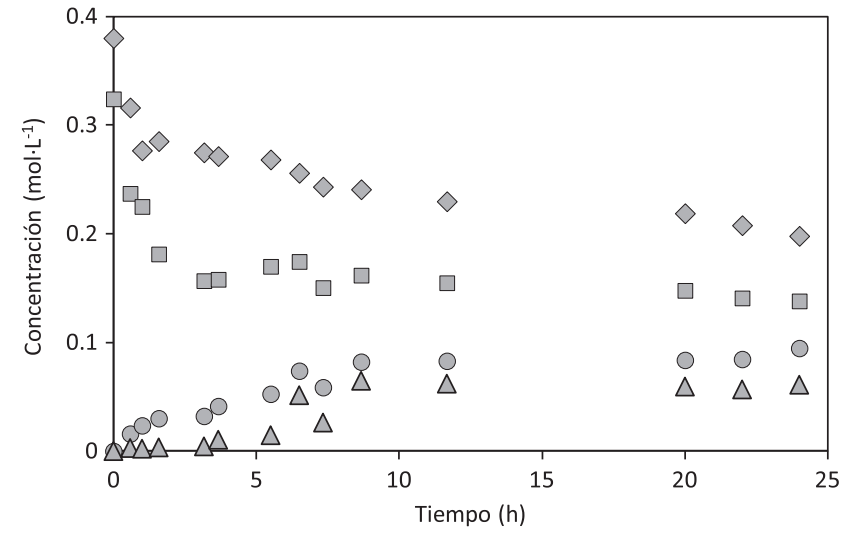

Fig. 2 - Profiles of reactants and products obtained with $\mathrm{Pd} / \mathrm{Mg}-\mathrm{Zr}$ catalysts at $323 \mathrm{~K} . \mathrm{C} 3(\diamond), \mathrm{C5}(\square), \mathrm{C} 8(0)$ and C13 ( $\triangle)$.

aldolization is enhanced by the presence of palladium due to the interaction between this metal and the double $\mathrm{C}-\mathrm{C}$ bonds present in furfural, C8 and C13 compounds. Taking into account that this interaction increases as the molecular size and the number of double bonds increases [21], the adsorption of $\mathrm{C} 13$ is strong enough for catalyzing the retro-aldolization reaction (when the C13 interacts with a medium-strength basic sites) and also producing side-products (when interacting with other kinds of sites). On the other hand, the higher adsorption extent of C8 and C13 increases condensated adducts deposition over the catalytic surface, as it was observed in the TPO analyses of the used catalysts (Fig. 3). The main peaks observed in these patterns correspond to $\mathrm{CO}_{2}$ releases at $730 \mathrm{~K}$, temperature associated in previous works with the combustion of adsorbed C13 [14].

In order to corroborate the importance of the retroaldolization reactions, a separate experiment using $\mathrm{C} 8$ as single reactant and $\mathrm{Pt} / \mathrm{Mg}-\mathrm{Al}$ as a catalyst was performed. It was detected more than $16 \%$ of $\mathrm{C} 13$ adduct after $8 \mathrm{~h}$ of reaction and almost $2 \%$ of free furfural. These results indicate the decomposition of C8into furfural and acetone over $\mathrm{Pd} / \mathrm{Mg}-\mathrm{Al}$ and the subsequent reaction between the furfural and C8, obtaining the $\mathrm{C} 13$ adduct. The retroaldolization in the second step was also tested using C13 as a single reactant. More than $3 \%$ of $\mathrm{C} 8$ was obtained after $8 \mathrm{~h}$. In order to validate a reaction mechanism in which both direct and reverse reactions exist for the formation and decomposition of C8 and C13 adducts, a systematic study at different reactants ratio was carried out: from furfural excess (3:1) to acetone excess (1:3), obtaining a remarkable decrease in the $\mathrm{C} 13 / \mathrm{C} 8$ ratio in all the cases (comparing with the previous results obtained with the bulk materials at same reaction conditions [13]). The kinetic model

Table 2 - Final conversions, selectivities and carbon balance (defined according to equations (1)-(4)) obtained after $24 \mathrm{~h}$ of furfural-acetone aldol condensation at $323 \mathrm{~K}$ using different bifunctional catalysts and pattern mixed oxides under inert or reducing atmosphere conditions. (Results related to bulk materials are summarized from Ref. [13]).

\begin{tabular}{|c|c|c|c|c|c|c|c|}
\hline \multirow[t]{2}{*}{ Catalyst } & \multirow[t]{2}{*}{ Atmosphere } & \multicolumn{2}{|c|}{ Conversion (\%) } & \multicolumn{3}{|c|}{ Selectivity (\%) } & \multirow[t]{2}{*}{ Carbon balance (\%) } \\
\hline & & C3 & C5 & $\mathrm{C} 8$ & C13 & C6 & \\
\hline $\mathrm{Mg}-\mathrm{Zr}$ & $\mathrm{N}_{2}$ & 54.2 & 81.4 & 14.7 & 61.5 & 3 & 98.4 \\
\hline \multirow[t]{2}{*}{$\mathrm{Pd} / \mathrm{Mg}-\mathrm{Zr}$} & $\mathrm{N}_{2}$ & 50.5 & 73.4 & 29.2 & 30.6 & 8 & 86.0 \\
\hline & $\mathrm{H}_{2}$ & 77.8 & 62.8 & 28.5 & 34.8 & 5 & 94.3 \\
\hline $\mathrm{Mg}-\mathrm{Al}$ & $\mathrm{N}_{2}$ & 36.2 & 63.8 & 31.1 & 42.9 & 4 & 97.8 \\
\hline \multirow[t]{2}{*}{$\mathrm{Pd} / \mathrm{Mg}-\mathrm{Al}$} & $\mathrm{N}_{2}$ & 41.7 & 54.7 & 11.9 & 3.0 & 11 & 75.0 \\
\hline & $\mathrm{H}_{2}$ & 39.9 & 50.0 & 8.4 & 4.0 & 3 & 88.2 \\
\hline
\end{tabular}




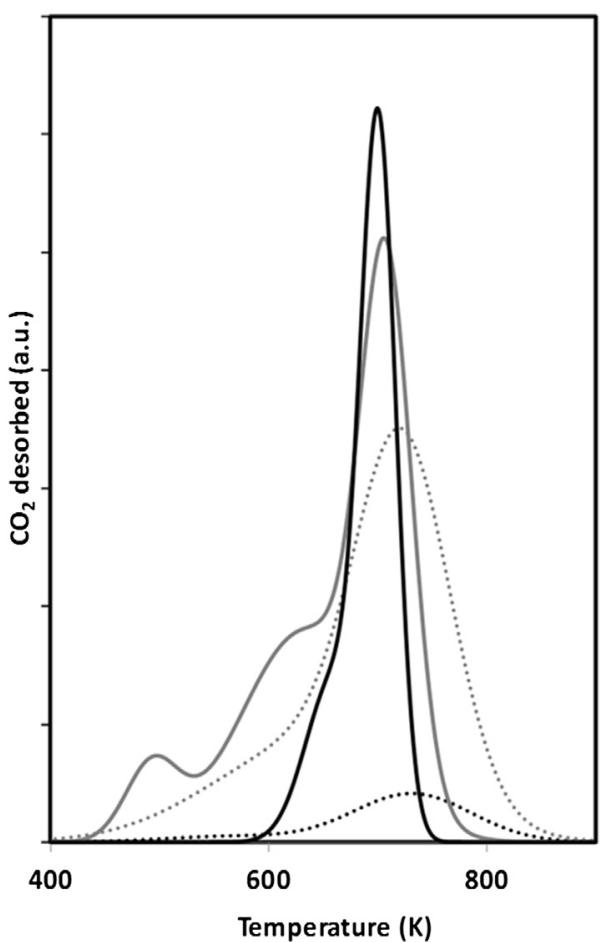

Fig. 3 - TPO profiles of the used catalysts ( 2 cycles): black line $\mathrm{Pd} / \mathrm{Mg}-\mathrm{Zr}$; gray line $\mathrm{Pd} / \mathrm{Mg}-\mathrm{Al}$. Catalysts used in the reactions with hydrogen are indicated in broken lines.

proposed considers that both steps (formation of C8 and C13 adducts) are reversible because of the retro-aldolization reaction. Concerning to the reaction orders, it was previously demonstrate that the rate-determining step in liquid-phase aldol condensations should involve medium-strength base sites and the formation of the carbanion intermediate [13]. Consequently, this reaction is considered to follow first order dependence on enolizable species (acetone and C8 adduct) and zero-th order on non-enolizable species (furfural and C13 adduct).

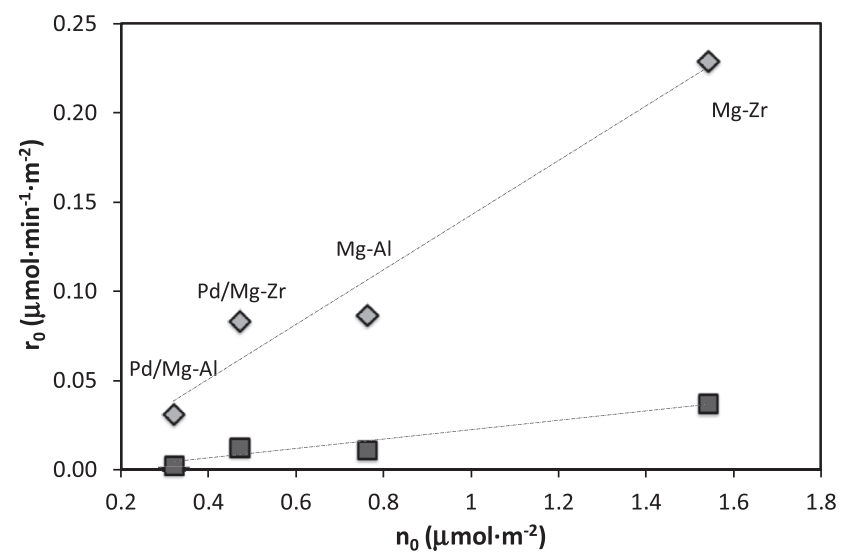

Fig. 4 - Initial formation rates of C6 $(\square)$ and C8 $(\diamond)$ on bifunctional catalysts as a function of medium-strength base sites density $\left(n_{0}\right)$. (Results related to bulk materials are summarized from Ref. [13]).
This model is consistent to a rate-determining step consisting on the abstraction of an $\alpha-\mathrm{H}$ atom from the ketone (C8 formation) or C8 adduct (C13 formation). In a good agreement with this proposal, it was observed that C8 and C6 formation rates follow a linear dependence with the concentration of medium strength basic sites, as observed in Fig. 4 . Thus, the modification of surface basicity during impregnation (Fig. 1) reduces also the formation of the condensation adducts. These results obtained by $\mathrm{CO}_{2}$-TPD are in agreement with the $\mathrm{O}$ 1s signals obtained by XPS. The $\mathrm{O}$ 1s peak can be related to the global basic strength of each catalyst, in such a way that lower values of binding energy are related to stronger basicity [22]. The values obtained for palladium catalysts $(528.6 \mathrm{eV}$ for $\mathrm{Pd} / \mathrm{Mg}-\mathrm{Zr}$ and $528.8 \mathrm{eV}$ for $\mathrm{Pd} / \mathrm{Mg}-\mathrm{Al}$ ) were very similar, indicating analogous basicity. These binding energies are, in both cases, lower than the corresponding to the parent mixed oxides (529.0 eV Mg- $\mathrm{Zr}$ and $530.0 \mathrm{eV} \mathrm{Mg-Al).}$

The results of the statistical analysis using the abovementioned kinetic model as well as the $r^{2}$ values are summarized in Table 3, whereas the goodness of the model for predicting the evolution of reactants and products concentration is shown in Supplementary Information (Fig. S2). Comparing these values with those obtained with the mixed oxides, an increase of the value of $k_{1}$ was observed in all the cases, whereas a decrease in $k_{2}$ and higher values of retroaldolization constants were observed, explaining the lower values of C13 selectivities obtained for the Pd-promoted catalysts.

Since the role of Pd mainly relies on their ability to activate hydrogen molecule, the methodology was modified using hydrogen instead of nitrogen to pressurize the reactor. Final acetone and furfural conversions obtained after $24 \mathrm{~h}$ of aldol condensation in presence of a reducing atmosphere, as well as data related to the selectivities and carbon balance obtained is depicted in Table 2. Concentration profiles (not shown here) follow the same trend as in the absence of hydrogenation, confirming that the presence of reducing atmosphere do not affect the main reaction mechanism. C8 and C13 selectivities include the condensed isomers and some partiallyhydrogenated $\mathrm{C} 8$ and $\mathrm{C} 13$ compounds. All the adducts were analyzed by GC-MS and it can be concluded that the soft reaction conditions only allow the hydrogenation of the double $\mathrm{C}-\mathrm{C}$ bonds of the carbon chains, whereas $\mathrm{C}-\mathrm{O}$ bonds are never hydrogenated.

The reducing atmosphere increases the C13 selectivity (from 30.6 to $34.8 \%$ with $\mathrm{Pd} / \mathrm{Mg}-\mathrm{Zr}$ and from 3.0 to $4.0 \%$ with $\mathrm{Pd} / \mathrm{Mg}-\mathrm{Al}$ ) and enhances the carbon balance closure, reaching

Table 3 - Kinetic constants $\left(\mathrm{min}^{-1}\right.$ ) for the fitting of the experimental results to the proposed kinetic model. Reaction 1: condensation of acetone and furfural yielding C8 adduct; reaction 2: condensation of $\mathbf{C 8}$ and furfural yielding C13 adduct. Negative numbers refer to reverse reaction. Reaction 3: acetone self-condensation; reaction 4: formation of insoluble surface deposits.

\begin{tabular}{cccccccc} 
& $k_{1}$ & $k_{2}$ & $k_{-1}$ & $k_{-2}$ & $k_{3}$ & $k_{4}$ & $r^{2}$ \\
\hline $\mathrm{Pd} / \mathrm{Mg}-\mathrm{Zr}$ & 0.00302 & 0.0402 & 0.0089 & 0.127 & 0.00014 & 0.0016 & 0.98 \\
$\mathrm{Pd} / \mathrm{Mg}-\mathrm{Al}$ & 0.00396 & 0.0148 & 0.0109 & 0.016 & 0.00011 & 0.0013 & 0.99 \\
\hline
\end{tabular}


similar values than without metal. Thus, the presence of palladium and a reducing atmosphere, lead to a partial hydrogenation of the condensation adducts, minimizing the interaction of condensated adducts and the metal surface and preventing the permanent deposition of heavier condensed products on the catalyst surface.

The concentration of partially-hydrogenated C8 was, in both cases, higher than C13 (around 30\% of the whole C8 and less than $5 \%$ of the whole C13), indicating that C8 is easier to hydrogenate than C13. Taking into account that only the C8 adduct reacts with furfural yielding $\mathrm{C} 13$, the hydrogenation of this product can be an additional limitation in the C13 formation.

\subsection{Consequences of Pd addition on the catalyst stability}

In order to check the effect of Pd addition on the stability of the studied catalysts, two subsequent batch experiments were conducted with the catalysts, with inert and reducing atmosphere. In all the cases, the catalysts were filtered and dried before being again introduced in the reactor with a new aqueous solution of furfural and acetone and the aldol condensation was studied at the same conditions as in the first cycles. Considering that the lowest values of furfural conversion in the first cycle were obtained for $\mathrm{Pd} / \mathrm{Mg}-\mathrm{Al}$ under reducing conditions (50\%), the study of catalyst stability was carried out comparing the reusability of spent catalyst after reaching $50 \%$ of furfural conversion in the first cycle. Results obtained after $24 \mathrm{~h}$ of the second cycle are shown in Fig. 5.

The results obtained with the parent mixed oxides are also shown in this figure for comparison purposes. Using $\mathrm{Mg}-\mathrm{Zr}$ as a support, the presence of Pd under inert atmosphere does not improve the recyclability results: with lower final carbon balance, the loss of C13 selectivity was almost 60\% (better result than with the parent material, ca. 90\%). However, the decrease in the C8 selectivity was much higher (50\% with $\mathrm{Pd}$ whereas it was less than $15 \%$ without it). However, if the reactions are carried out under reducing atmosphere, the bifunctional catalysts were significantly more stable, with less than $25 \%$ of decrease in the selectivities of each product and reaching the highest values in the second cycle for all the parameters studied (selectivities and carbon balance). These results confirm that the partial hydrogenation improves the catalytic performance by minimizing side reactions and catalyst fouling effects (as suggested by the increase of the carbon balance). Concerning to the results of $\mathrm{Pd} / \mathrm{Mg}-\mathrm{Al}$, the presence of partial hydrogenation produces a less pronounced effect than the observed for $\mathrm{Pd} / \mathrm{Mg}-\mathrm{Zr}$, indicating that the main reason of its low activity is not related to the deposition of products over the active centers. In this case, the acetone self-condensation has an important role, as can be observed with the values of the carbon balance closure.

In general terms, add to catalyst fouling, two different deactivation causes are reported in these catalytic reactions: leaching of active compounds from the catalyst in aqueous medium and structural changes into the catalyst. Metal leaching was discarded by ICP-OES analysis of the metallic constituents in the reaction media, with less than $1 \%$ of the catalytic composition ( $\mathrm{Mg}, \mathrm{Zr}$ and $\mathrm{Al}$ ) dissolved into the
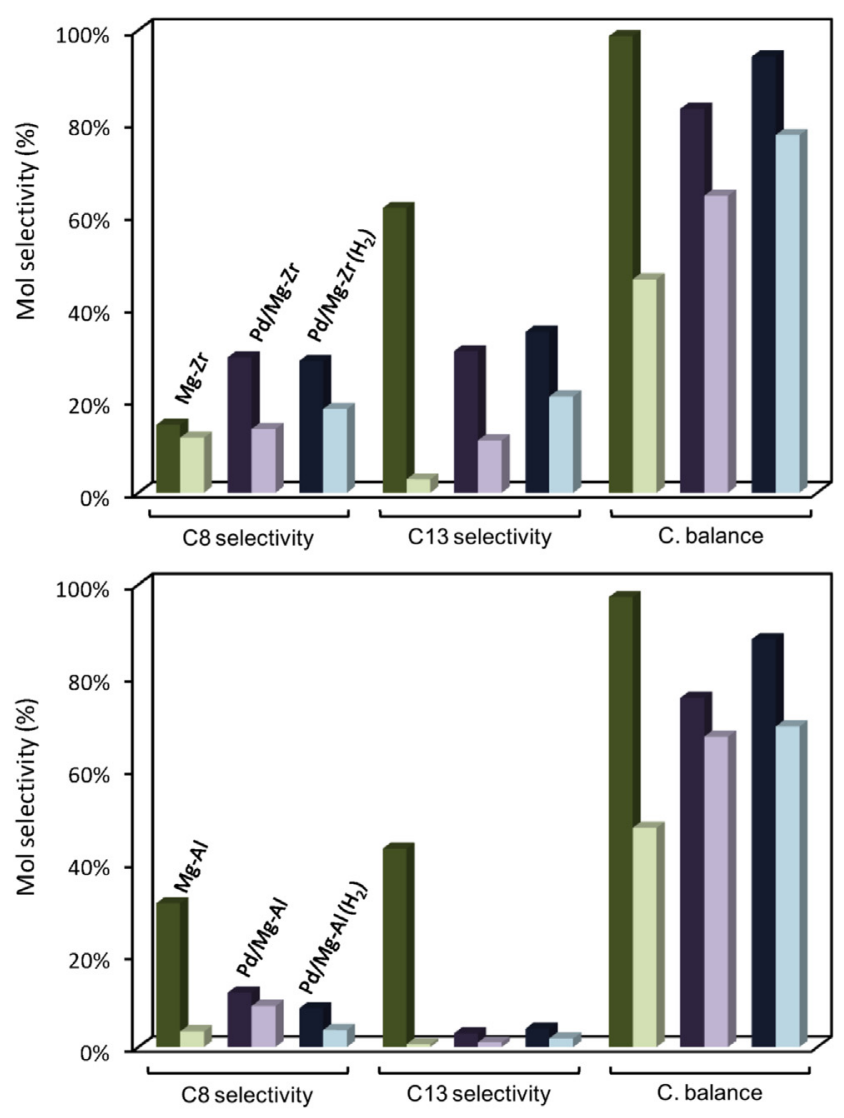

Fig. 5 - Results obtained after two cycles of $24 \mathrm{~h}$ reaction with the studied catalysts with inert and reducing atmosphere. Dark colors correspond to the first cycle and light series correspond to the results obtained in the second reaction.

aqueous phase after $24 \mathrm{~h}$ reaction time. In order to see possible structural changes of the catalysts, TEM analyses of the spent catalysts were carried out (Supplementary Information, Fig. S3). Both catalysts present different surface morphologies, the spongy structure representative of mixed oxides has resulted into laminar and needle surfaces. These reorganizations are compatible with hydroxides formation (in the case of $\mathrm{Mg}-\mathrm{Zr}$ ) or a compact crystalline structure (in the case of $\mathrm{Mg}-\mathrm{Al}$ ) [23]. Consequently, the numbers of defects and anchoring points have been altered, modifying the catalytic activity. Surface area of spent catalysts is congruent with these micrographs, with areas of $111 \mathrm{~m}^{2} \mathrm{~g}^{-1}$ and $92 \AA$ of pore diameter for $\mathrm{Pd} / \mathrm{Mg}-\mathrm{Zr}$ (almost the same area but smaller pore diameters than fresh catalyst) and $2 \mathrm{~m}^{2} \mathrm{~g}^{-1}$ and $26 \AA$ for $\mathrm{Pd} / \mathrm{Mg}-\mathrm{Al}$ (which implies high decrease comparing with the fresh material).

\section{Conclusions}

Aldol condensation of furfural and acetone was carried out on $\mathrm{Pd} / \mathrm{MgO}-\mathrm{ZrO}_{2}$ and $\mathrm{Pd} / \mathrm{MgO}-\mathrm{Al}_{2} \mathrm{O}_{3}$ catalysts, using both an inert and reductive atmosphere. Palladium addition to mixed oxides catalysts decreases both the catalytic activity for 
aqueous-phase aldol condensation and the selectivity for C8 and $\mathrm{C} 13$ adducts. Strong adsorption of products on the surface and formation of insoluble condensates hinders the evolution of the reaction. Catalysts reusability improves when aldolization is carried out in a $\mathrm{H}_{2}$ atmosphere. The bi-functional catalysts are more stable than the parent mixed oxides at these conditions, although a validation at continuous-flow conditions is still needed. C13 partial hydrogenation increases adducts solubility, avoiding their deposition on catalyst surface and increasing catalyst re-usability.

\section{Acknowledgments}

This work was supported by the Spanish Government (contracts CTQ2008-06839-C03-02 and CTQ2011-29272-C04-02). L. Faba thanks the Government of the Principality of Asturias for a Ph.D. fellowship (Severo Ochoa Program).

\section{Appendix A. Supplementary data}

Supplementary data related to this article can be found at http://dx.doi.org/10.1016/j.biombioe.2013.06.008.

\section{R E F E R E N C E S}

[1] IEA. World energy outlook world, 2007. Paris: International Energy Agency; 2007.

[2] Sim REH, Mabee W, Saddler JN, Taylor M. An overview of second generation biofuels technologies. Bioresour Technol 2010;101(6):1570-80.

[3] Huber GW, Chheda JN, Barret CJ, Dumesic JA. Production of liquid alkanes by aqueous phase processing of biomassderived carbohydrates. Science 2005;308:1446-50.

[4] Käldström M, Kumar N, Murzin DY. Valorization of cellulose over metal supported mesoporous materials. Catal Today 2011;167(1):91-5.

[5] Zhang J, Zhuang J, Lin L, Liu S, Zhang Z. Conversion of $\mathrm{D}$-xylose into furfural with mesoporous molecular sieve MCM-41 as catalyst and butanol as the extraction phase. Biomass Bioenergy 2012;39:73-7.

[6] Karimi K, Kheradmandinia S, Taherzadeh MJ. Conversion of rice straw to sugars by dilute-acid hydrolysis. Biomass Bioenergy 2006;30(3):247-53.

[7] Käldström M, Kumar N, Heikkilä T, Murzin DY. Pillared H-MCM-36 mesoporous and H-MCM-22 microporous materials for conversion of levoglucosan: influence of varying acidity. Appl Catal A 2011;397(1-2):13-21.

[8] Barret CJ, Chheda JN, Huber GW, Dumesic JA. Single-reactor process for sequential aldol-condensation and hydrogenation of biomass-derived compounds in water. Appl Catal B 2006;66(1-2):111-8.
[9] Faba L, Díaz E, Ordóñez S. Improvement on the catalytic performance of $\mathrm{Mg}-\mathrm{Zr}$ mixed oxides for furfural-acetone aldol condensation by supporting on mesoporous carbons. ChemSusChem 2013;6(3):463-73.

[10] Wenkin M, Touillaux R, Ruiz P, Delmon B, Devillers M. Influence of metallic precursors on the properties of carbon-supported bismuth-promoted palladium catalysts for the selective oxidation of glucose to gluconic acid. Appl Catal A 1996;148(1):181-99.

[11] Sádaba I, Ojeda M, Mariscal R, Richards R, Granados ML. $\mathrm{Mg}-\mathrm{Zr}$ mixed oxides for aqueous aldol condensation of furfural with acetone: effect of preparation method and activation temperature. Catal Today 2011;167(1):77-83.

[12] Dedsuksophon W, Faungnawakij K, Champreda V, Laosiripojana N. Hydrolysis/dehydration/aldolcondensation/hydrogenation of lignocellulosic biomass and biomass-derived carbohydrates in the presence of $\mathrm{Pd} /$ $\mathrm{WO}_{3}-\mathrm{ZrO}_{2}$ in a single reactor. Bioresour Technol 2011;102(2):2040-6.

[13] Faba L, Díaz E, Ordóñez S. Aqueous-phase furfural-acetone aldol condensation over basic mixed oxides. Appl Catal B 2012;113-114:201-11.

[14] Faba L, Díaz E, Ordóñez S. Performance of bifunctional $\mathrm{Pd} / \mathrm{MxNyO}(\mathrm{M}=\mathrm{Mg}, \mathrm{Ca} ; \mathrm{N}=\mathrm{Zr}, \mathrm{Al})$ catalysts for aldolization-hydrogenation of furfural-acetone mixtures. Catal Today 2011;164(1):451-6.

[15] Narayanan S, Krishna K. Hydrotalcite-supported palladium catalysts: part I: preparation, characterization of hydrotalcites and palladium on uncalcined hydrotalcites for CO chemisorption and phenol hydrogenation. Appl Catal B 1998;174:221-9.

[16] Narayanan S, Krishna K. Hydrotalcite-supported palladium catalysts: part II. Preparation, characterization of hydrotalcites and palladium hydrotalcites for $\mathrm{CO}$ chemisorption and phenol hydrogenation. Appl Catal A 2000;198(1-2):13-21.

[17] Scanlon JT, Willis DE. Calculation of FID relative response factors using the effective carbon number concept. J Chromatogr Sci 1985;23:333-40.

[18] Aramendía M, Borau V, Jiménez C, Marinas JM, Moreno A. Comparative measurements of the dispersion of $\mathrm{Pd}$ catalyst on $\mathrm{SiO}_{2} \cdot \mathrm{AlPO}_{4}$ support using TEM and $\mathrm{H}_{2}$ chemisorption. Colloid Surf A 1996;106(2-3):161-5.

[19] Leon M, Díaz E, Bennici S, Vega A, Ordóñez S, Auroux A. Adsorption of $\mathrm{CO}_{2}$ on hydrotalcite-derived mixed oxides: sorption mechanisms and consequences for adsorption irreversibility. Ind Eng Chem Res 2010;49:3663-71.

[20] Arena F, Dario R, Parmaliana A. A characterization study of the surface acidity of solid catalysts by temperature programmed methods. Appl Catal A 1998;170(1):127-37.

[21] Di Cosimo JI, Acosta A, Apesteguía CR. Allylic alcohol synthesis by gas-phase hydrogen transfer reduction of unsaturated ketones. J Mol Catal A 2005;234(1-2):111-20.

[22] Funks D, Dorfman S, Felsteiner J, Gordon A, Postnikov AV, Borstel G. Dynamics of the perovskite interphase boundary under pressure. Surf Sci 1996;352-354:879-82.

[23] Chheda JN, Dumesic JA. An overview of dehydration, aldol-condensation and hydrogenation processes for production of liquid alkanes from biomass-derived carbohydrates. Catal Today 2007;123(1-4):59-70. 